\title{
Effect of Stitch Lengths and Yarn Counts on Areal Density and Drape Behaviour of Different Weft Knitted Single Jersey Structures
}

\author{
Emdadul Haque ${ }^{1}$, Md Shamim Alam ${ }^{2, *}$ \\ ${ }^{1}$ Department of Textile Engineering, Ahsanullah University of Science and Technology, Dhaka, Bangladesh \\ ${ }^{2}$ Department of Textile Engineering, South East University, Dhaka, Bangladesh
}

Email address:

emdad.haque@aust.edu (E. Haque), shamim100486@gmail.com (Md S. Alam)

* Corresponding author

\section{To cite this article:}

Emdadul Haque, Md Shamim Alam. Effect of Stitch Lengths and Yarn Counts on Areal Density and Drape Behaviour of Different Weft Knitted Single Jersey Structures. American Journal of Applied Scientific Research. Vol. 2, No. 6, 2016, pp. 33-37. doi: 10.11648/j.ajasr.20160206.11

Received: June 24, 2016; Accepted: October 20, 2016; Published: November 21, 2016

\begin{abstract}
This paper aimed at analysis on the effects of stitch length and Yarn Count on GSM and drape behavior of weft knitted single jersey fabrics. In this research work different types of weft knitted single jersey fabrics have been used like as single jersey plain, single lacoste, double lacoste and polo pique fabric. As drape is one of the most important properties of textile materials so drape ability of a fabric should measure. Here drape ability of a fabric was determined using the instrument Cusick drape tester and is expresses in terms of drape co-efficient. It was found after completing the work GSM increases gradually with the decrease of stitch length. Double lacoste has highest GSM and single Jersey Plain has lowest GSM. GSM increases gradually in coarser yarn. Drape co-efficient decreases gradually with the increase of stitch length. Double lacoste has highest drape co-efficient and polo pique has lowest drape co-efficient. Drape co-efficient decreases gradually in finer yarn.
\end{abstract}

Keywords: Drape Co-efficient, Knitted Fabric, Yarn Count, GSM, Stitch

\section{Introduction}

Knitted fabric consists of loops, which intermeshed each other. Loops can have different appearance, according to shape of yarn path. Thus, different structural elements exist in the knitted fabric [1]. Knitting is frequently used method for fabric production. Knitted fabric is unique in structure that it possesses a high order of elasticity and recovery. In other word, unlike woven or bonded fabrics which possess a low degree of elongation, knitted fabric can be stretched to considerable length and will gradually return to its original shape. Knit fabrics provide comfortable wear to almost any style of garment [2].

The dimensional stability of knit fabrics is an important area of the knitting industry. Stitch length, yarn count, structure of fabric influence the dimensional stability of fabric [3]. These various factors influence the dimensional stability as well as the bending length and drape co-efficient of the knitted fabrics. Dimensional changes occur during production or washing or wearing. Drape is the ability of a fabric to assume a graceful appearance in use. It is an important property to textiles materials which allows fabric to orient itself into graceful folds or pleats as a result of force of gravity. A fabric is said to possess a good drape ability when its configuration is pleasant to eye [4].

A circular specimen of diameter $30 \mathrm{~cm}$ is supported on a circular disc of diameter $18 \mathrm{~cm}$. When doing so the unsupported area of the fabric drapes over edge of the supporting disc. If the specimen is an object say a card board draping would not occur and hence the area of projection from the periphery would equal to the area of the solid object [5]. When the fabric is supported, it will assume the folded configuration due to gravity and the shape of the projected area will not be circular [6]. This study has been carried out to investigate the Effect of stitch length and yarn count on areal density and drape behavior of different weft knitted single jersey structures. 


\section{Materials and Methods}

\subsection{Materials}

For this study $100 \%$ Cotton $\mathrm{z}$ twisted yarn was used with different count like as $28 \mathrm{Ne}, 30 \mathrm{Ne}$ and $32 \mathrm{Ne}$. Electronic Balance, GSM Cutter, Cusick Drape Tester, Counting Glass, Pin, Drape Paper, Marker Pen, Scissor and Scale were also used here. Single Jersey Circular Knitting Machine that was used for knitting is shown below with specification.

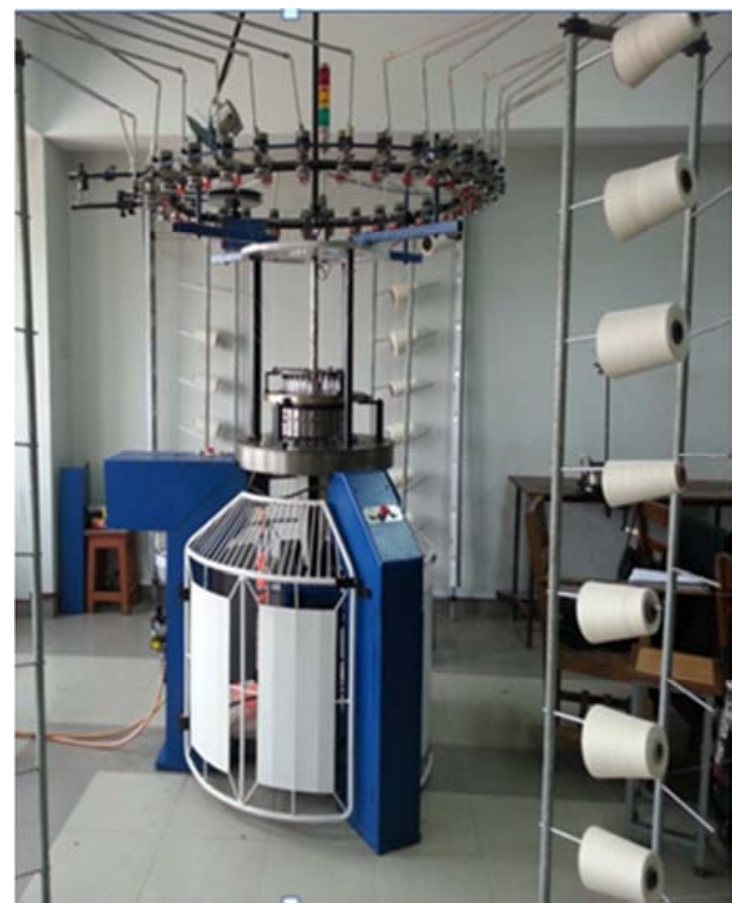

Figure 1. Single jersey circular knitting machine.

Table 1. Specifications of Single jersey circular knitting machine.

\begin{tabular}{l|l}
\hline Machine Type & Single knit \\
\hline Machine gauge & $24 \mathrm{G}$ \\
Cylinder diameter & 10 inch \\
No. of feeders & 30 \\
No. of tracks & 4 \\
Total no. of needles & 744 \\
Type of needle & Latch needle \\
Rotation of cylinder & Clockwise \\
Creel capacity & 60 \\
Oiling system & pneumatic \\
\hline
\end{tabular}

\subsection{Methodology}

To complete this research work following procedures were followed and are summarized sequentially.

\subsubsection{Knitted Fabric Production Process}

Needle set-out and cam arrangements were set in 3 tracks to produce plain structures. Then 30 cones of $28 \mathrm{Ne}$ yarn were set in the creel stands. The diameter of Quality Adjustment Pulley (QAP) was adjusted to $15.46 \mathrm{~cm}$ to maintain stitch length of $2.66 \mathrm{~mm}$. Then fabric was produced by using 30 feeders. After that diameter of QAP was adjusted to $16.66 \mathrm{~cm}$ to maintain stitch length $2.86 \mathrm{~mm}$ and produced another sample of plain structure. Then stitch length was changed to $3.07 \mathrm{~mm}$ by adjusting diameter of QAP to $17.86 \mathrm{~cm}$ and produced another sample of plain structure.
After producing above three samples of three different stitch length of same count, yarn count were changed to $30 \mathrm{Ne}$ and $32 \mathrm{Ne}$ to produce three different stitch lengths.By following the same sequence nine samples of single lacoste, double lacoste and polo pique structures were produced at three different stitch length. In case of single lacoste and polo pique structures 28 cones and 28 feeders were used as they have four courses structural repeat.

Table 2. Following are the details of produced samples.

\begin{tabular}{|c|c|c|c|c|}
\hline $\begin{array}{l}\text { Sample } \\
\text { number }\end{array}$ & Structure & $\begin{array}{l}\text { Stitch length } \\
(\mathrm{mm})\end{array}$ & $\begin{array}{l}\text { Yarn count } \\
(\mathrm{Ne})\end{array}$ & $\begin{array}{l}\text { Structure } \\
\text { code }\end{array}$ \\
\hline 1. & Single jersey plain & 2.66 & 28 & SJP \\
\hline 2. & Single jersey plain & 2.86 & 28 & SJP \\
\hline 3. & Single jersey plain & 3.07 & 28 & SJP \\
\hline 4. & Single jersey plain & 2.66 & 30 & SJP \\
\hline 5. & Single jersey plain & 2.86 & 30 & SJP \\
\hline 6. & Single jersey plain & 3.07 & 30 & SJP \\
\hline 7. & Single jersey plain & 2.66 & 32 & SJP \\
\hline 8. & Single jersey plain & 2.86 & 32 & SJP \\
\hline 9. & Single jersey plain & 3.07 & 32 & SJP \\
\hline 10. & Single lacoste & 2.66 & 28 & SL \\
\hline 11. & Single lacoste & 2.86 & 28 & SL \\
\hline 12. & Single lacoste & 3.07 & 28 & SL \\
\hline 13. & Single lacoste & 2.66 & 30 & SL \\
\hline 14. & Single lacoste & 2.86 & 30 & SL \\
\hline 15. & Single lacoste & 3.07 & 30 & SL \\
\hline 16. & Single lacoste & 2.66 & 32 & SL \\
\hline 17. & Single lacoste & 2.86 & 32 & SL \\
\hline 18. & Single lacoste & 3.07 & 32 & SL \\
\hline 19. & Double lacoste & 2.66 & 28 & DL \\
\hline 20. & Double lacoste & 2.86 & 28 & DL \\
\hline 21. & Double lacoste & 3.07 & 28 & DL \\
\hline 22. & Double lacoste & 2.66 & 30 & DL \\
\hline 23. & Double lacoste & 2.86 & 30 & DL \\
\hline 24. & Double lacoste & 3.07 & 30 & DL \\
\hline 25. & Double lacoste & 2.66 & 32 & DL \\
\hline 26. & Double lacoste & 2.86 & 32 & DL \\
\hline 27. & Double lacoste & 3.07 & 32 & DL \\
\hline 28. & Polo pique & 2.66 & 28 & PP \\
\hline 29. & Polo pique & 2.86 & 28 & $\mathrm{PP}$ \\
\hline 30. & Polo pique & 3.07 & 28 & $\mathrm{PP}$ \\
\hline 31. & Polo pique & 2.66 & 30 & PP \\
\hline 32. & Polo pique & 2.86 & 30 & PP \\
\hline 33. & Polo pique & 3.07 & 30 & $\mathrm{PP}$ \\
\hline 34. & Polo pique & 2.66 & 32 & PP \\
\hline 35. & Polo pique & 2.86 & 32 & PP \\
\hline 36. & Polo pique & 3.07 & 32 & PP \\
\hline
\end{tabular}

\subsubsection{Measurement of GSM (Gram per Square Meter)}

GSM of the fabrics were measured according to the BS 2471:1978. The samples were conditioned in standard atmospheric condition of $20^{\circ} \mathrm{C} \pm 2^{\circ} \mathrm{C}$ temperature and $65 \% \pm 2 \%$ relative humidity. Samples were laid on a flat horizontal surface for removing wrinkles without stretching. Five test specimens were cut by using the GSM cutter from each structure. The specimens were weighted by the electronic balance machine. The formula to find out the GSM of fabric is

$$
\mathrm{GSM}=\mathrm{m} \times 100
$$

Here, $\mathrm{m}$ is the mass in gram of the specimen.

After calculating the GSM from 5 different places average 
GSM was taken and presented in table 3.

\subsubsection{Measurement of Drape Co-efficient}

The appropriate diameter of the template and corresponding size of paper ring was $30 \mathrm{~cm}$. The choice was depended upon the stiffness of the sample. The limper the sample the smaller the template and paper ring required [7]. Firstly, test sample was calendared and conditioned in standard atmosphere. The selected template $(30 \mathrm{~cm})$ was placed on the specimen and marked round it. Then a pin was pushed through the template center in order to make a small hole in the middle of specimen. After cutting the specimen it was placed on the disc $(18 \mathrm{~cm})$ of Cusick drape tester and the lid was covered. A paper ring was placed on the lid around the locating disc. After that the light of the drape tester was switched on. A shadow of the specimen was found on the paper [8]. Then the shadow was drawn on the paper. Drape co-efficient of fabrics were calculated using the formula $\mathrm{F}=\frac{W_{s}-W_{d}}{W D-W_{d}} \times 100 \%$

Where,

$\mathrm{WD}=$ weight of the paper whose area is equal to the area of the specimen.

$\mathrm{Wd}=$ weight of the paper whose area is equal to the area of the supporting disc.

$\mathrm{Ws}=$ weight of the paper whose area is equal to the projected area of the specimen.

\section{Results and Discussions}

The effects of yarn count and stitch length on fabric areal density and drape behavior of different weft knitted single jersey structures are shown in the Table 3, Table 4 and figure 2 to 14 and discussed below.

Table 3. GSM in Different Stitch Length and Structure at $28 \mathrm{Ne}, 30 \mathrm{Ne}$ and $32 \mathrm{Ne}$.

\begin{tabular}{lllll}
\hline $\begin{array}{l}\text { Yarn } \\
\text { count }\end{array}$ & $\begin{array}{l}\text { Fabric } \\
\text { structure }\end{array}$ & $\begin{array}{l}\text { GSM of } \\
\mathbf{2 . 6 6 m m} \text { stitch } \\
\text { length }\end{array}$ & $\begin{array}{l}\text { GSM of } \\
\mathbf{2 . 8 6 m m} \\
\text { stitch length }\end{array}$ & $\begin{array}{l}\text { GSM of } \\
\mathbf{3 . 0 7} \text { mm } \\
\text { stitch length }\end{array}$ \\
\hline \multirow{2}{*}{$28 \mathrm{Ne}$} & DL & 174.30 & 167.30 & 144.20 \\
& PP & 168.40 & 154.15 & 140.05 \\
& SL & 151.75 & 144.80 & 134.80 \\
& SJP & 148.80 & 142.70 & 129.30 \\
& DL & 159.65 & 145.65 & 136.90 \\
$30 \mathrm{Ne}$ & PP & 149.70 & 140.05 & 133.85 \\
& SL & 144.50 & 134.10 & 126.65 \\
& SJP & 140.10 & 133.20 & 123.65 \\
& DL & 153.90 & 139.95 & 133.45 \\
$32 \mathrm{Ne}$ & PP & 141.05 & 133.90 & 127.85 \\
& SL & 136.45 & 131.55 & 121.95 \\
& SJP & 135.40 & 130.65 & 120.20 \\
\hline
\end{tabular}

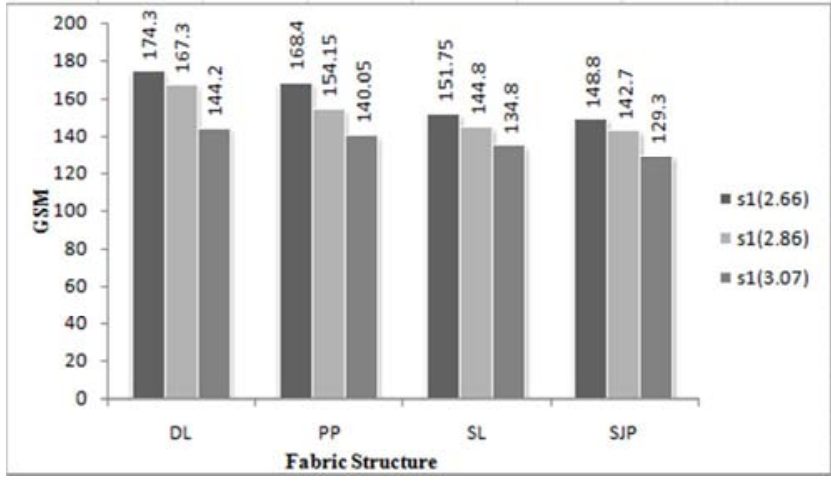

Figure 2. Effect of stitch length and structure on GSM at $28 \mathrm{Ne}$.

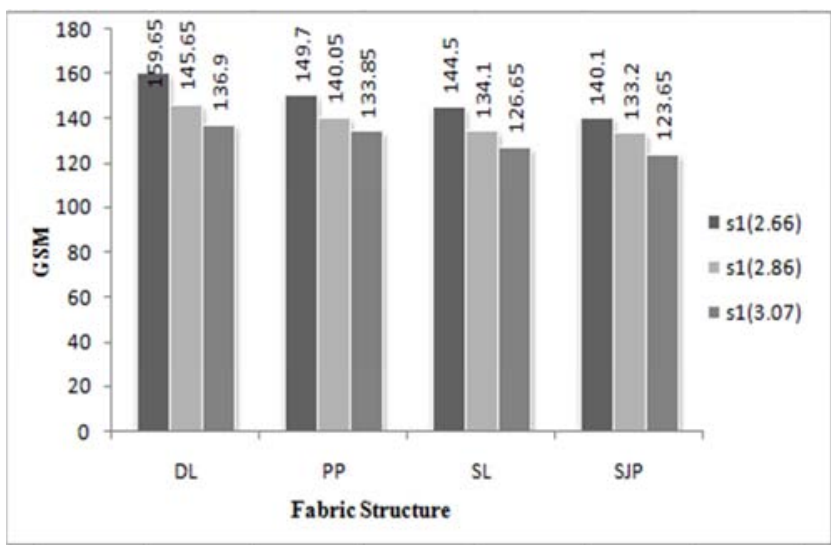

Figure 3. Effect of stitch length and structure on GSM at $30 \mathrm{Ne}$.

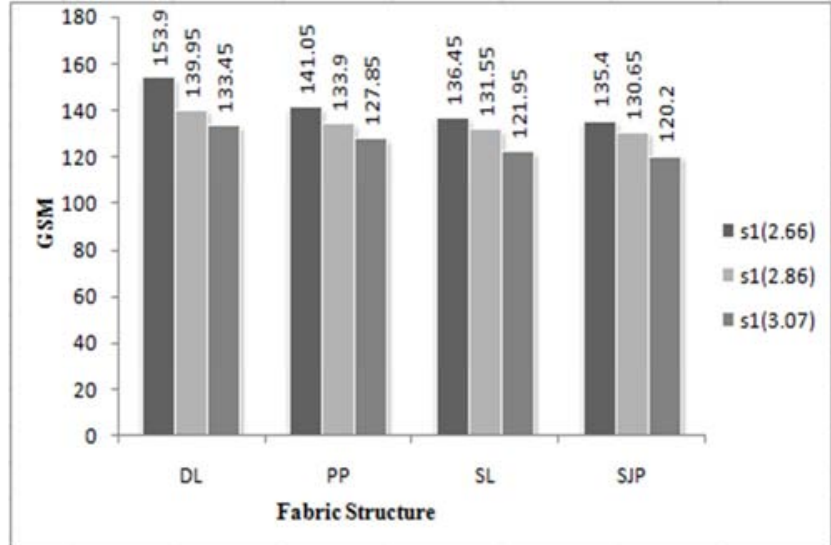

Figure 4. Effect of stitch length and structure on GSM at $32 \mathrm{Ne}$.

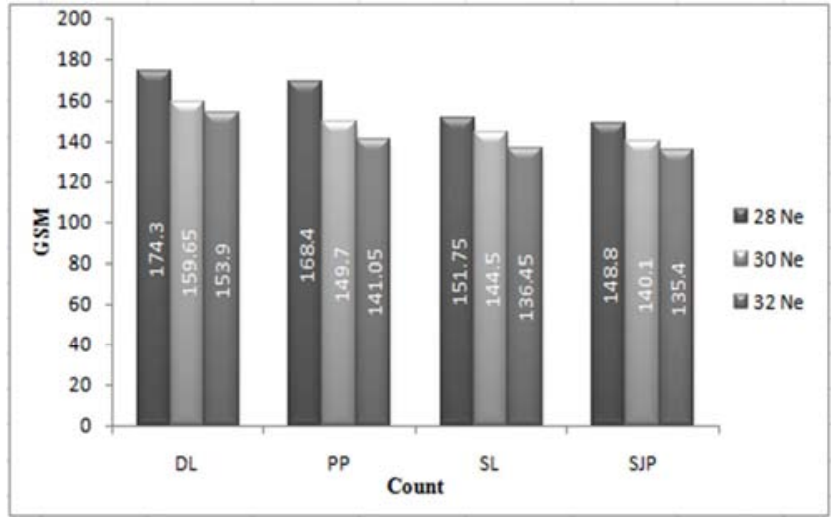

Figure 5. Effect of count and structure on GSM at 2.66mm stitch length. 


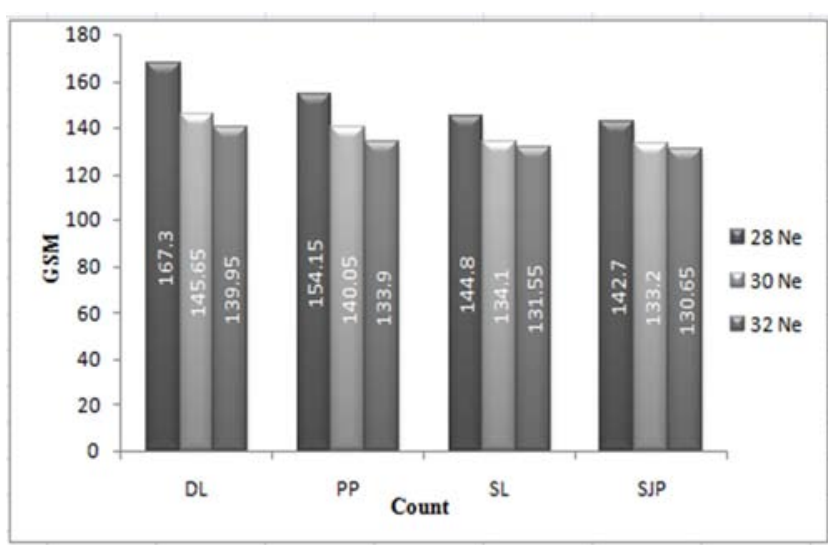

Figure 6. Effect of count and structure on GSM at 2.86mm stitch length.

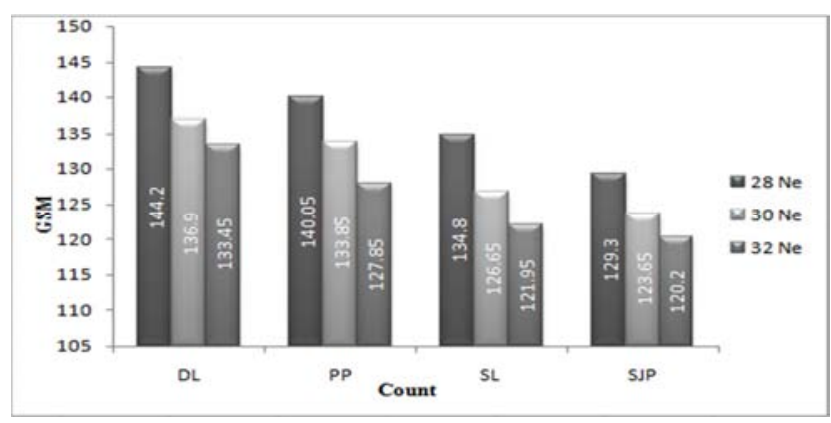

Figure 7. Effect of count and structure on GSM at 3.07mm stitch length.

Table 3 and figure 2 to 7 represent the effects of yarn count and stitch length on fabric areal density. It has been observed that the value of GSM has decreased with the increase of yarn count within the same stitch length. When yarn count gets finer its mass per unit length decreases. As a result GSM decreases. This phenomenon is found common to all four structures. Nowkeeping the yarn count and stitch length constant when we compare the value of GSM among different structures we can see that plain fabric possesses the lowest value and double lacoste possess the highest value of GSM. Plain structure consists of knit loop stitches only while double lacoste has more tuck stitches in its structural repeat. At the tucked places more yarn consumption is occurred which increase the thickness of fabric. As a result double lacoste possesses more GSM than other three structures. It can also be seen from the graph that the value of GSM has gradually decreased according to the sequence - double lacoste, polo pique, single lacoste and single jersey plain.

Table 4. Drape Co-Efficient (\%) in Different Stitch Length and Structure at $28 \mathrm{Ne}, 30 \mathrm{Ne}$ and $32 \mathrm{Ne}$.

\begin{tabular}{lllll}
\hline Yarn count & Fabric name & S1 (2.66mm) & S2 (2.86mm) & S3 (3.07mm) \\
\hline \multirow{3}{*}{$28 \mathrm{Ne}$} & DL & 39.50 & 35.33 & 34.83 \\
& SL & 33.33 & 33.00 & 31.00 \\
& PP & 31.67 & 30.00 & 25.67 \\
& SJP & 35.33 & 31.50 & 29.33 \\
$30 \mathrm{Ne}$ & DL & 38.50 & 35.17 & 34.17 \\
& SL & 32.83 & 30.17 & 29.33 \\
& PP & 31.00 & 28.00 & 25.00 \\
$32 \mathrm{Ne}$ & SJP & 32.00 & 31.17 & 31.67 \\
& DL & 36.17 & 34.83 & 34.00 \\
& SL & 31.50 & 28.83 & 26.33 \\
& PP & 28.00 & 26.50 & 23.33 \\
\hline
\end{tabular}

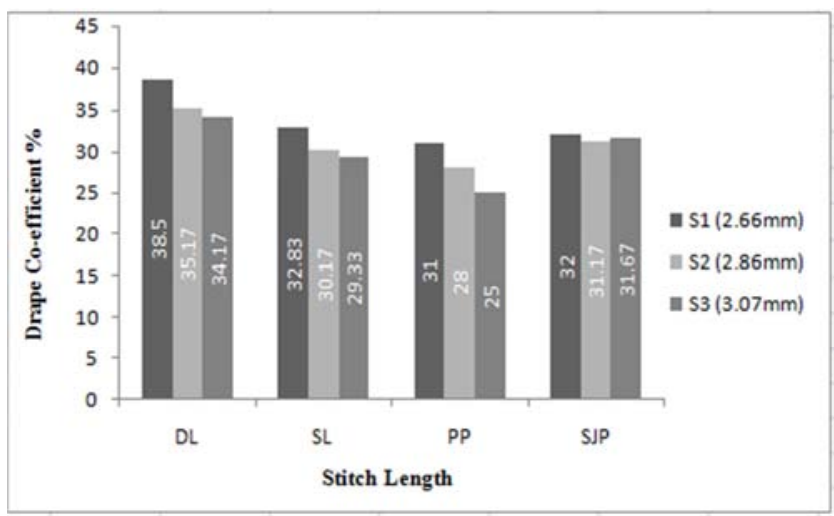

Figure 8. Effect of stitch length and structure on drape co-efficient at $28 \mathrm{Ne}$.

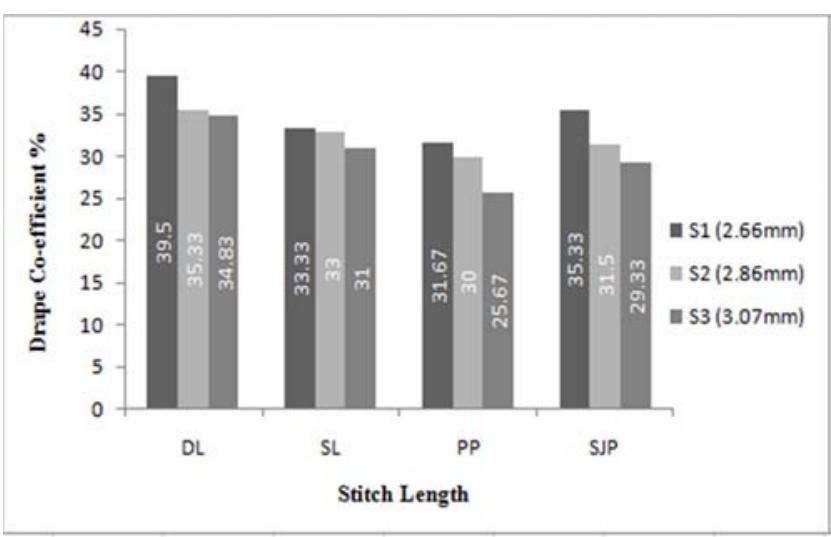

Figure 9. Effect of stitch length and structure on drape co-efficient at $30 \mathrm{Ne}$.

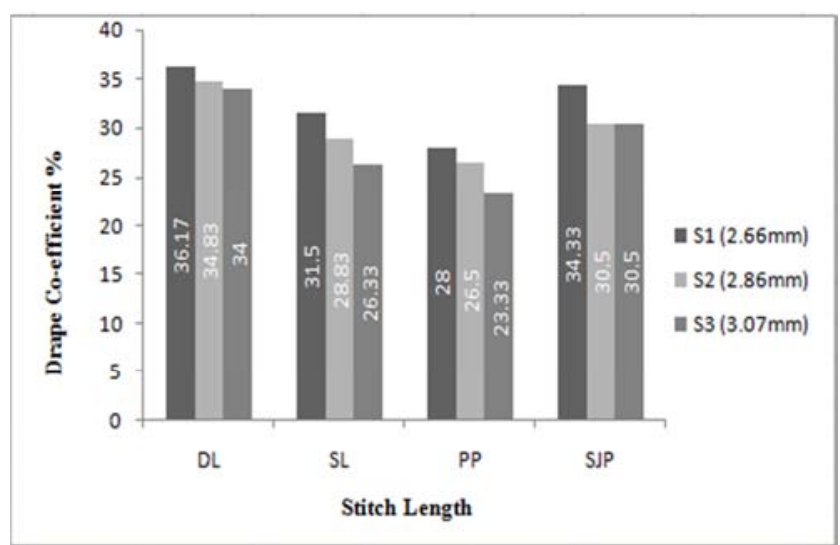

Figure 10. Effect of stitch length and structure on drape co-efficient at 32 $\mathrm{Ne}$.

It has been shown in table 4 and figure 8 to 10 that percentage of drape co-efficient has decreased as stitch length increases within the same yarn count. Like bending length drape property of a fabric depends on its compactness. The more compact the fabric the more percentage of drape coefficient. When stitch length increases fabric density as well as compactness decreases if the other parameters such as machine gauge, yarn count, twist per inch, structure, etc. remain the same.So limpness of fabric increases causing decreases ofdrape co-efficient. This phenomenon is found common to all four structures. 


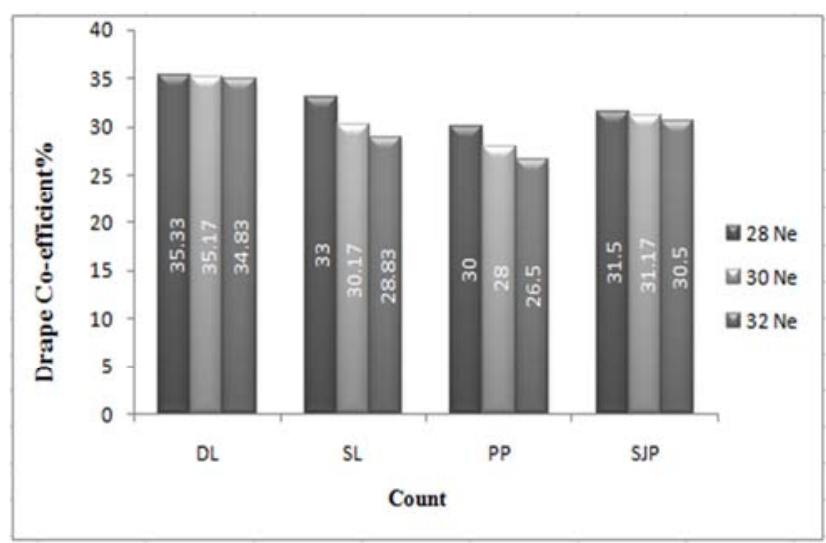

Figure 11. Effect of count and structure on drape co-efficient at $2.66 \mathrm{~mm}$.

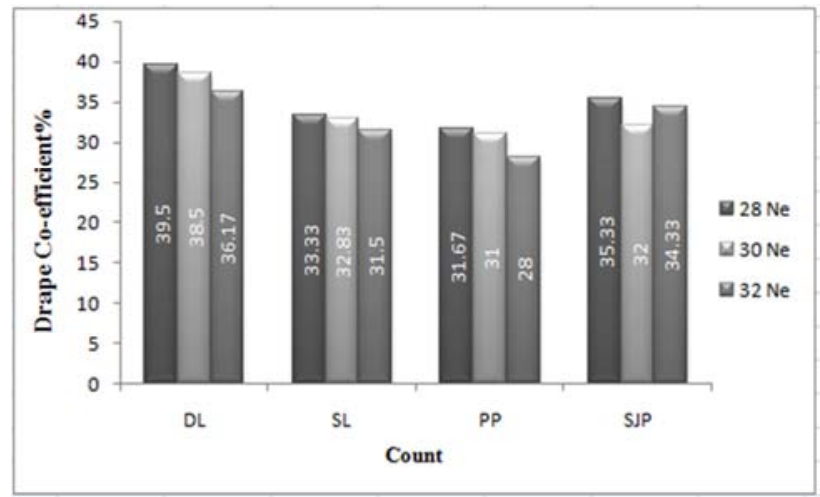

Figure 12. Effect of count and structure on drape co-efficient at $2.86 \mathrm{~mm}$.

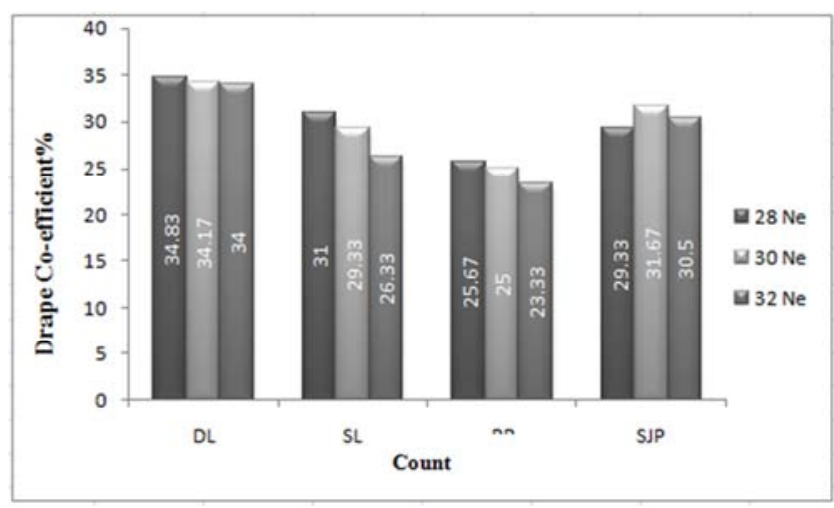

Figure 13. Effect of count and structure on drape co-efficient at $3.07 \mathrm{~mm}$.

Table 4 and figure 11 to 13 represent the effects of yarn count and structures on drape behavior. It has been observed that percentage of drape co-efficient has decreased as yarn count gets finer within the same stitch length. When yarn count gets finer its mass per unit length decreases. Finer yarn is softer and limper than coarser yarn. So fabric produced with finer yarn become softer and limper if the other parameters such as machine gauge, stitch length, twist per inch, structure, etc. remain the same. So limpness of fabric increases causing decreases of drape co-efficient. This phenomenon is found common to all four structures.

Now keeping the yarn count and stitch length constant if we compare the drape coefficient percentage among different structures we can see that polo pique possesses the lowest value and double lacoste possesses the highest value. This is because polo pique has $50 \%$ tuck stitch and $50 \%$ knit stitch in its structural repeat which makes it less dense than double lacoste. It can also be seen from the graph that bending length has gradually decreased according to the sequence double lacoste, single lacoste and polo pique. Drape coefficient of single jersey plain was ignored during the comparison because of its excessive curling property during drape test.

\section{Conclusion}

The results of this research work indicating that areal density (GSM) and drape co-efficient of weft knitted fabrics are directly related to the stitch length, yarn count and knitted structures. It was observed that higher GSM and higher drape co-efficient were obtained with smaller stitch length. It has been identified that areal density (GSM) of double lacoste, polo pique, single lacoste and single jersey plain decreased sequentially. It has also been seen that the drape co-efficient of double lacoste, single lacoste and polo pique decreased sequentially. Drape co-efficient of single jersey plain was not considerable because it curled extremely during test. We have also found that higher GSM and higher drape co-efficient and wider fabrics are produced with coarser yarns.

\section{References}

[1] David J Spencer., "From hand knitting to hand frame knitting," in Knitting Technology, third, vol. 103. D J Spencer, Ed. Cambridge: Woodhead Publishing Limited, 2001, pp. 7.

[2] C. Iyer, W. Schach\&B. Mallel, "Knitting Technique," in Circular Knitting, second, C. Iyer, Ed. Bamberg: Meisenbach Bamberg,1995, pp. 6.

[3] David J Spencer., "Stitches produced by varying the sequence of the needle loop," in Knitting Technology, third, vol. 103. D J Spencer, Ed. Cambridge: Woodhead Publishing Limited, 2001, pp. 90.

[4] Marian Louise Gaucher., "The Physical Properties That Influence The Drape of Knitted Fabrics" M.Sc. thesis, the University of Manitoba, Manitoba, 1979, pp. 6.

[5] P. Angappan \& R. Gopalakrishnan., "Testing of Fabric," in Textile Testing, fourth, P. Angappan\& R. Gopalakrishnan, Ed. Tamil Nadu: S.S.M.I.T.T. Staff and Students' Co-op Stores Limited,1997, pp. 327-329.

[6] L. Kokas-palicska, I. Szücs, and Z. Borka., "Characterisation of Fabric Drape Using Spectral Functions Methods Used to Calculate Drape Behavoir of," vol. 5, no. 3, 2008, pp. 75-85.

[7] K. Tsai, M. Tsai, P. Ning Wang, T. Shyr, "New approach to directly acquiringethe drape contours of various fabrics," vol.17.no. 3(74). 2009, pp.54-56.

[8] Y. Abdin, I. Taha, a. El-Sabbagh, and S. Ebeid, "Description of draping behaviour of woven fabrics over single curvatures by image processing and simulation techniques," Compos. Part B Eng., vol. 45, no. 1, 2013, pp. 792-799.

[9] P. Pratihar, "Static and Dynamics Drape Of Fabric: An Emerging Arena of Fabric Evaluation," vol. 3, no. 5, 2013, pp. 1007-1011.

[10] P. Gnanavel and T. Ananthakrishnan, "Textile Science \& Engineering Volume Based Measurement of Fabric Drape using Surfer Software and Studies on Effect of Influencing Factors," vol. 4, no. 4, 2014, pp. 55-56. 